\title{
Design of Digitally Controlled DC-DC Boost Converter for the Operation in DC Microgrid
}

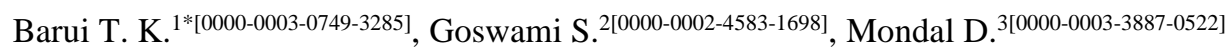 \\ ${ }^{1}$ Indian Institute of Engineering Science and Technology, Botanic Garden, 711103, Howrah, India; \\ ${ }^{2}$ Cognizant Technology Solutions, Unitech Infospace, DH Block (Newtown), 700156, Kolkata, India; \\ ${ }^{3}$ RCC Institute of Information Technology, Canal South Road, Beliaghata, 700015, Kolkata, India
}

\section{Article info:}

Paper received:

The final version of the paper received:

Paper accepted online:
September 12, 2020

December 9, 2020

December 14, 2020
*Corresponding email:

tuhinkumar93@gmail.com

\begin{abstract}
Renewable energy sources (RESs) are becoming increasingly important day by day to tranquilize the world's energy crisis and consume fossil fuels in the lower rung. A microgrid system that assimilates clean and green energy-based sources such as solar, wind, and biogas is acquiring much prominence over the conventional grid-based power systems in this day and age. For the up and running of the inexhaustible energy sources in the AC power network, numerous conversions of the power sources occur. In the process of conversion, some amount of power is lost, which minimizes conversion efficiency. However, with the increasing use of DC loads and Distributed Energy Resources (DERs), DC Microgrid could be more beneficial than the conventional AC power system by avoiding several types of drawbacks. This paper demonstrates an efficient system of digitally controlled boost converter for the parallel operation in DC microgrid. Here, the converter of $2.5 \mathrm{~kW} 400 \mathrm{~V}$ is designed and implemented to validate its functioning in a Microgrid. The whole system has been simulated in MATLAB with an input voltage range of 220-380 V. It has been found that the designed converter can maintain the desired output voltage in the DC Busbar at and around $400 \mathrm{~V}$. Finally, some simulation results have been presented to analyze the converter's operational characteristics and effectiveness in the practical domain.
\end{abstract}

Keywords: DC Microgrid, Renewable energy, DC-DC Boost Converter, Digital Controller.

\section{Introduction}

For the recent development in the electrical power supply network, the DC power transmission and distribution system are coming shortly. For the remote area electricity supply, microgrids play a vital role by interconnecting the consumers with the power sources. Here, RESs are the most suitable option for this operation than the conventional grid-based power system as these sources are locally and readily available anywhere. This work's primary purpose is the design of a DC-DC Boost converter with a digital control system for an efficient operation of a DC microgrid system.

A DC power system network of $400 \mathrm{~V}$ buses has been selected as provided in Fig. 2. The DC bus is connected to local loads and a utility grid with a grid-tied inverter. The output voltage of all the sources must be equal to the DC bus voltage to maintain the power flow's stability.

As there is an irregularity in these power sources and the output voltage varies with the increase of loads, properly controlled converters are needed to maintain the bus voltage. Any mismatching of electrical parameters will lead to system failure.

It has been observed that the no-load voltage of the solar PV and DC generator drops to a certain level at its full load with the increase of load current. Therefore, the drop in output voltage will lead to system instability which cannot maintain DC Busbar voltage at $400 \mathrm{~V}$.

So, a boost converter is necessary to maintain a constant output voltage at the DC busbar. Apart from that, specific ripple contents in the power sources' output voltage are at their full load. A perfect selection of the inductor and capacitor in the converter minimizes the ripples. Fig. 3 shows a simple schematic of the DC-DC Boost Converter.

Here, MOSFET acts as a switching device operated by digital PWM signals. IGBT can be also be used for switching devices, but MOSFET switching would be more efficient. 


\section{Literature Review}

There is an outstanding opportunity to utilize clean and green energy sources for the far-flung area electrification in any country. Nowadays, all fossil fuels-based power sources are being replaced with green energy sources such as solar PV, wind, and biogas. With the beginning of the rural electrification process, renewable energy-based microgrids are gradually obtaining higher significance over the utility grid. From an economic point of view, constructing a utility grid is not possible in some areas. Microgrids lowers the extra investments in the construction of power transmission, and side by side, the consumers can get an uninterrupted supply of power [1,2]. It is a network of electrical power sources that may be $\mathrm{AC}$ or DC. As our electrical system comprises an AC power network, AC microgrids have precedence over the enduring infrastructure. But due to some disadvantages in the AC system, such as synchronization, harmonics, system stability, reactive power loss, poor power factor $[3,4]$. Apart from this, output power from solar and battery storage is DC, and the proliferating use of DC loads such as LED, TV, and Laptop. DC microgrids are accomplishing prominence over AC Microgrids and have become the most efficient one for distributing and transmission of electricity to the end-users in future electrification process. As a microgrid is a cluster of all energy sources, power generation from biogas can play a significant role in the sustained supply of electricity to the consumers from solar PV and wind energy are unavailable [5].

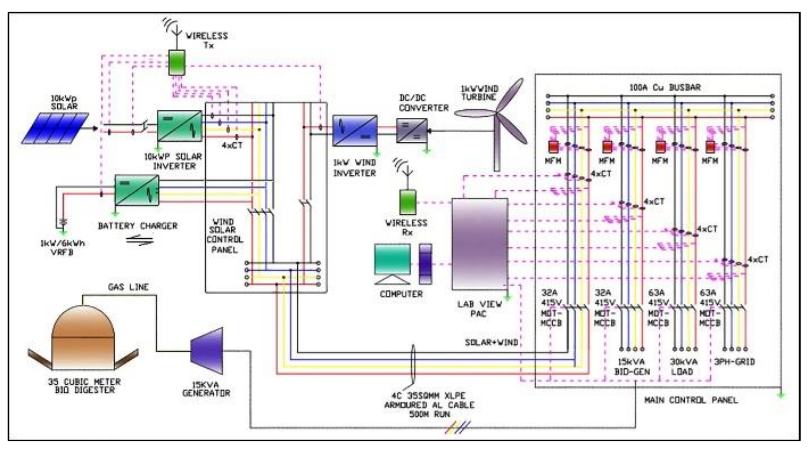

Figure 1 - Single Line Diagram of hybrid AC Microgrid [6]

The single line diagram of the AC Hybrid Microgrid has been shown in Fig. 1 [6]. The illustration shown in Fig. 1. is a cluster of power sources such as solar PV, wind, biogas, and battery energy storage (BES). The power generated from these power sources is directly fed to the utility grid through numerous modes of power conversion techniques such as DC to AC in the case of Solar PV and BES. It may result in power losses, an increase of harmonics, and minimization of efficiency [3, 6, 7, 8]. In order to overcome these problems, a schematic diagram of renewable energy sources integrated with DC Microgrid has been depicted in Fig. 2.

This DC system's advantage is that lessening of power conversions and ease of control of the whole system. The problems related to harmonics and reactive power loss can be eliminated with the proposed scheme. As there is no point of voltage, phase, and frequency matching in DC Microgrid, it is not required to install additional systems to maintain reasonably economical stability. The charging and discharging procedure for the BES can be easily effortlessly implemented in this system without power conversion. The whole DC system can alleviate the stability problem of the AC Microgrid. Therefore, with technology advancement for using DC power distribution and HVDC power transmission networks, an efficient and advanced technology-based power converter has been designed and implemented in this work [7, 10-12].

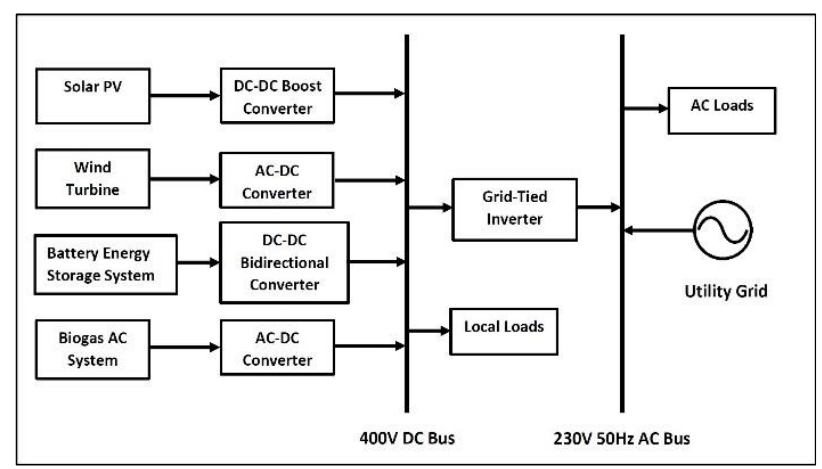

Figure 2 - A proposed block diagram of a DC Microgrid

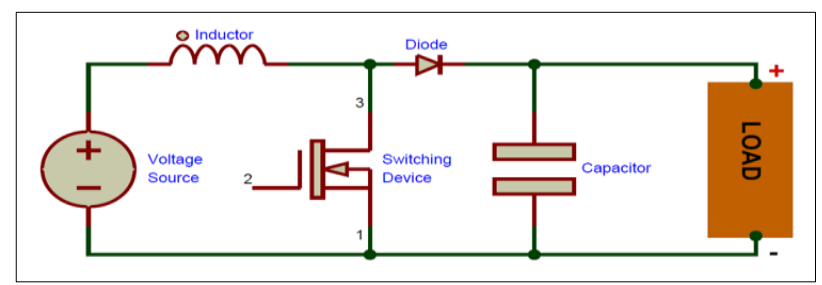

Figure 3 - Schematic of the DC-DC Boost Converter

As the RESs are irregular, efficient technology is imperative to draw the maximum useable power and decrease power loss. Here, power electronic devices could be the most preferred ones to transfer the maximum amount of power and easily maintain a stable DC bus voltage. Power electronic devices such as high voltage converters can deliver power to the loads by maintaining a constant voltage with proper power management techniques [13-15]. As in the DC Microgrid, various converters require to be connected in parallel linked to different energy sources, so the bus voltage needs to be maintained constant throughout for the whole system's stable operation [16]. A proper controller of the converters is to be designed for easy and reliable operation of an entire system in DC Microgrid [4, 17, 18]. As there are several drawbacks in the hardware implementation of the controller such as lowering of the efficiency, increasing use of hardware components, and power loss [19], and as the output of power sources consists of ripples voltage [20], digital control methods have gained importance for its operational reliability and flexibility [21, 22, 23]. Current control methods are extensively used in the converters for better performance and simple design [24]. The output voltage of these energy sources alters with the 
increase of loads. The sources like solar PV, wind, BES, and biogas generators have been considered for the DC Microgrid. Several converters are required to be connected in stacks with the power sources linked to the DC busbar.

The foremost objective of this work is to make an efficient power converter with the least conversion losses. A digital control system has been designed and implemented in the converter model, which consists of an Analog to Digital Converter (ADC), Digital controller, and PWM block. Furthermore, according to that, a digitally controlled 2.5 kW DC-DC Boost Converter of an output voltage of $400 \mathrm{~V}$ has been simulated in MATLAB, and its performance characteristics have been studied. The controller has been modeled in $\mathrm{z}$-domain with a typical gain value $=0.8$ and sampling time $=1$. Here, ADC has been used to quantize the physical signal, and then the quantized signal has been passed through the controller. The digital pulse is generated through a PWM generator of switching frequency $100 \mathrm{kHz}$ for driving the MOSFET. The performance of the system has been analyzed and mentioned in detail in the following sections.

\section{Research Methodology}

\subsection{System modeling and implementation}

Only The proposed HV converter with a closed-loop control system consists of the following components:

a) a $2.5 \mathrm{~kW}$ DC-DC Boost Converter of $400 \mathrm{~V}$;

b) a switching device of MOSFET which digital PWM drives;

c) digital controller.

The modeling of these components is presented as follows.

3.2 Modelling and operation of the DC-DC boost converter

The boost converter is made up of four elements, as shown in Fig. 3. In this work parameters of the elements are calculated as per the requirement of the system. The inductor and capacitor values are determined as $230 \mu \mathrm{H}$ and $500 \mu \mathrm{F}$ from Eqs. (2) and (3), respectively. A diode of the breakdown voltage of $600 \mathrm{~V}$ has been chosen for the converter's proper operation, which prevents the reverse flow of current. The specifications of the DC-DC Boost Converter are shown in Table 1.

Table 1 - Specifications of DC-DC Boost Converter

\begin{tabular}{|c|c|c|}
\hline Sl. No. & Parameters & Values \\
\hline 1 & Input Voltage & $220 \mathrm{~V}-380 \mathrm{~V}$ \\
\hline 2 & Output Voltage & $399 \mathrm{~V}-400 \mathrm{~V}$ \\
\hline 3 & Rated Power & $2.5 \mathrm{~kW}$ \\
\hline 4 & Output Current & $6.25 \mathrm{~A}$ \\
\hline 5 & Inductor Value & $230 \mu \mathrm{H}$ \\
\hline 6 & Diode & $500 \mathrm{~V} / 4 \mathrm{~A}$ \\
\hline 7 & Inductor ripple current & $1.8 \mathrm{~A}$ \\
\hline 8 & MOSFET rating & $500 \mathrm{~V} / 18 \mathrm{~A}$ \\
\hline 9 & Switching frequency & $100 \mathrm{kHz}$ \\
\hline
\end{tabular}

In a boost converter or a step-up converter as shown in Fig. 3. the inductor is directly connected in series with the input voltage. A solid-state device (MOSFET) is connected across the voltage source which acts as a switch. A diode is connected after the inductor that allows only the forward conduction of the current. The converter output is connected to a load and a capacitor is connected parallel to the load. The converter operates in two modes, firstly the MOSFET is ON, i.e., $\mathrm{T}_{\mathrm{ON}}$ and the current flows across the inductor and return to the source as it is short circuited as

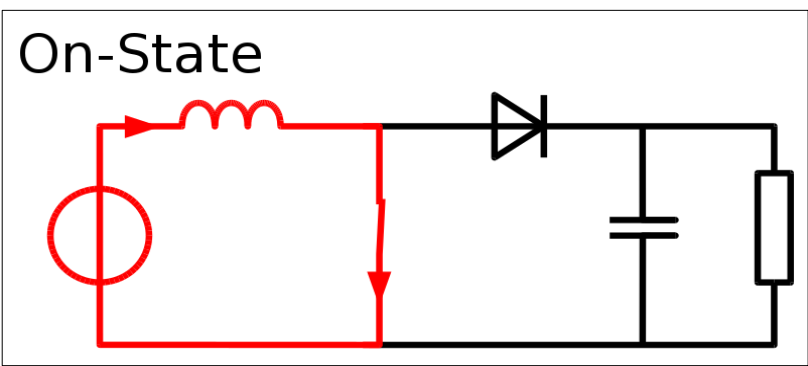

shown in Fig. 4.

Figure 4 - Converter operation when the MOSFET is ON

Hence energy is stored in the inductor. Secondly, the MOSFET is OFF, i.e., $\mathrm{T}_{\mathrm{OFF}}$ therefore the stored energy in the inductor added up with the input voltage are delivered to the load. Hence, the voltage is stepped up as shown in Fig. 5.

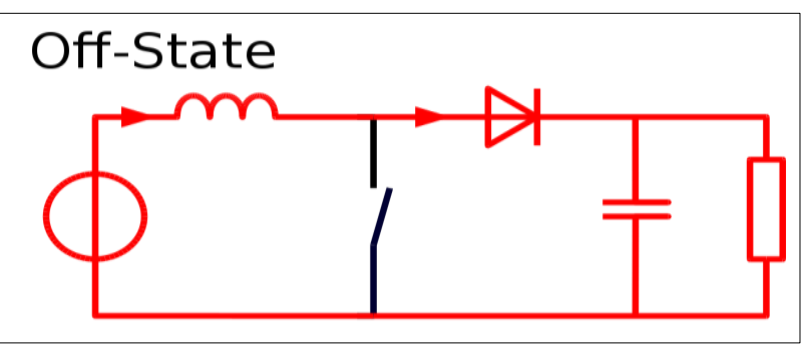

Figure 5 - Converter operation when the MOSFET is OFF

The total of $\mathrm{T}_{\mathrm{ON}}$ and $\mathrm{T}_{\mathrm{OFF}}$ is called the time $(\mathrm{T})$. So, proper modeling of the converter is essential for the reliable operation of the whole system. In continuous mode, the inductor current never falls to zero. It varies with time and is always greater than zero, as shown in Fig. 6.

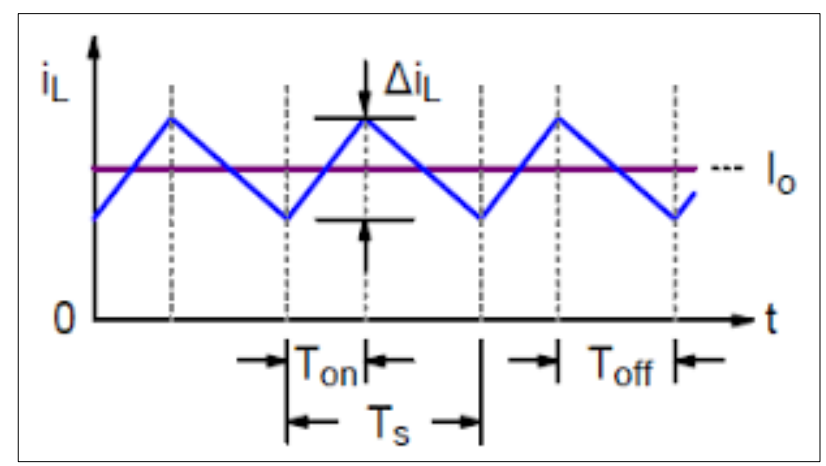

Figure 6 - Inductor Current during ToN and ToFF 
Here, as we know, the inductor ripple current is $30 \%$ of the output current. The ripple current $(\delta \mathrm{I})$ can be written as [25],

$\delta \mathrm{I}=0.3 * I_{o p}(\max ). * \frac{V_{o p}}{V_{i p}}$

As the maximum allowable current is $8.16 \mathrm{~A}$ then the inductor ripple current will be $3.25 \mathrm{~A}$. The inductor value can be calculated based on the ripple current and the switching frequency $\left(\mathrm{F}_{\mathrm{sw}}=100 \mathrm{kHz}\right)$. The inductor value (L) can be calculated as [25],

$L=\frac{V_{i p} *\left(V_{o p}-V_{i p}\right)}{\delta I * f_{S w} * V_{o p}}$

The minimum output capacitor value for the converter has been chosen as [25] for controlling the ripples in output voltage,

$C_{\text {omin }}=\frac{I_{\text {omax }} * D_{c y}}{f_{s w} * V_{r}}$

$C_{\text {omin }}=$ Minimum value of output capacitance

$I_{\text {omax }}=$ Maximum output current

$f_{s w}=$ Switching frequency

$V_{r}=$ Output voltage ripple

As the power sources' nominal full-load output voltage is $310 \mathrm{~V}$, the boost converter has to step up this voltage to the desired output voltage to meet load demand and maintain system stability. As the device is without a transformer, the switching of the MOSFET switching should be properly done as per the calculated duty cycle. The duty cycle $\left(D_{c y}\right)$ can be estimated as [25],

$D_{c y}=1-\frac{V_{i p}(\min .) * \eta}{V_{o p}}$

where,

$D_{c y}=$ Duty Cycle.

$V_{o p}=$ Output Voltage.

$V_{i p}=$ Input Voltage.

$I_{o p}=$ Output Current.

$\delta \mathrm{I}=$ Inductor Ripple Current.

$\eta=$ Efficiency of the converter.

The forward current rating of the diode must be equal to the maximum output current and can be calculated as [25],

$I_{d}=I_{\text {omax }}$

Where, $I_{d}=$ Forward current of the diode.

\subsection{Implementation of the Converter}

The converter with a closed-loop control system has been shown in Fig. 7. The whole system has been implemented using MATLAB software. The energy sources' output voltage has been estimated as $300 \mathrm{~V}$. The sources are connected to the HV DC-DC boost converter controlled by a digital controller. To extract the maximum power, the controller randomly collects voltage samples and sends the signal to the PWM generator for switching the MOSFET to adjust the output voltage. In this converter, a constant DC Voltage of $300 \mathrm{~V}$ has been used instead of an energy source. Here, the sensed output is first compared with the reference voltage and then send to the A/D converter for sampling purposes. The sampled error value is then sent to the Digital controller. The controlled value is then sent to the PWM generator circuit to generate PWM pulses for switching purposes. The output voltage is kept constant at $400 \mathrm{~V}$. A high peak current is necessary for switching the MOSFET. As per the calculated value of the duty cycle is 0.4 from Eq. (4), the solid-state device is appropriately switched to regulate the output voltage.

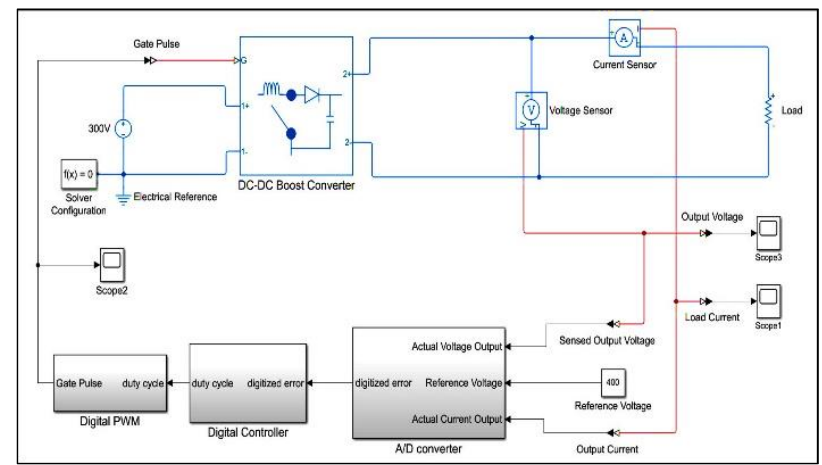

Figure 7 - Diagram of the designed Boost Converter in MATLAB

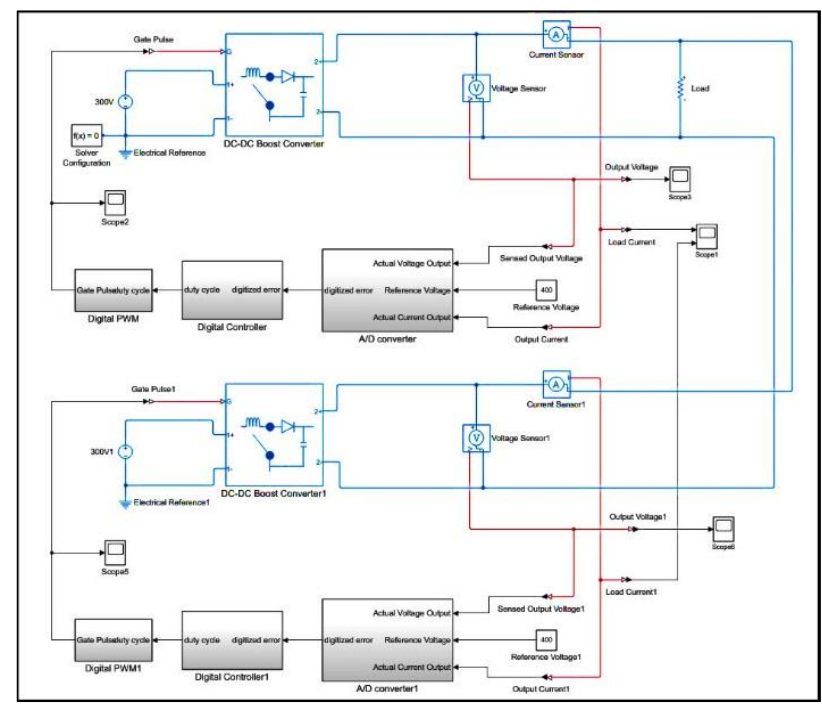

Figure 8 - Parallelly operation of two the Boost Converters

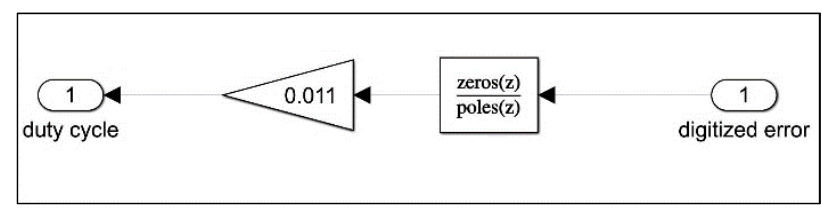

Figure 9 - Digital Controller block 
The digital controller shown in Fig. 9 has been modelled in Z-domain as [26] with a sampling time $=1$ and gain value $=0.8$. The transfer function of the controller has considered as follows:

$H(z)=0.8 *\left(\frac{Z-0.759}{Z-0.459}\right)$

For verification of the utility of the converter for the Microgrid operation, two converters are connected in parallel with a full load, as shown in Fig. 8, and the powersharing has been depicted in Fig. 14.

\section{Results}

The MATLAB simulation results are given in Table 2 by varying loads with a constant duty cycle. Furthermore, the results by varying the duty cycle with constant load are shown in Table 3.

Table 2 - Simulation Results for varying load resistance

\begin{tabular}{|c|c|c|c|c|}
\hline \multirow{2}{*}{$\begin{array}{c}\text { SI. } \\
\text { No. }\end{array}$} & \multicolumn{4}{|c|}{ Duty Cycle $=\mathbf{0 . 4 4}$} \\
\cline { 2 - 5 }$(\boldsymbol{\Omega})$ & $\begin{array}{c}\text { Voltage } \\
(\mathbf{V})\end{array}$ & $\begin{array}{c}\text { Current } \\
(\mathbf{A})\end{array}$ & $\begin{array}{c}\text { Ripple } \\
(\mathbf{V})\end{array}$ \\
\hline 1 & 200 & 401.5 & 2.005 & 1.8 \\
\hline 2 & 150 & 400.9 & 2.7 & 1.5 \\
\hline 3 & 85 & 400.5 & 4.69 & 1.7 \\
\hline 4 & 75 & 400.46 & 5.3 & 1.3 \\
\hline 5 & 64 & 400.2 & 6.26 & 1.4 \\
\hline
\end{tabular}

Table 3 - Simulation results for varying duty cycle

\begin{tabular}{|c|c|c|c|c|}
\hline \multirow{2}{*}{$\begin{array}{c}\text { Sl. } \\
\text { No. }\end{array}$} & \multicolumn{4}{|c|}{ Load = 64 $\Omega$, Switching Frequency $=\mathbf{1 0 0 ~ k H z}$} \\
\cline { 2 - 5 } & Duty Cycle & $\begin{array}{c}\text { Voltage } \\
\text { (V) }\end{array}$ & $\begin{array}{c}\text { Current } \\
(\mathbf{A})\end{array}$ & $\begin{array}{c}\text { Ripple } \\
\text { (V) }\end{array}$ \\
\hline 1 & 0.44 & 401.1 & 6.256 & 1.3 \\
\hline 2 & 0.38 & 400.5 & 6.25 & 1.3 \\
\hline 3 & 0.35 & 400.4 & 6.26 & 1.6 \\
\hline 4 & 0.58 & 400.9 & 6.23 & 1.8 \\
\hline 5 & 0.62 & 400.2 & 6.259 & 1.8 \\
\hline
\end{tabular}

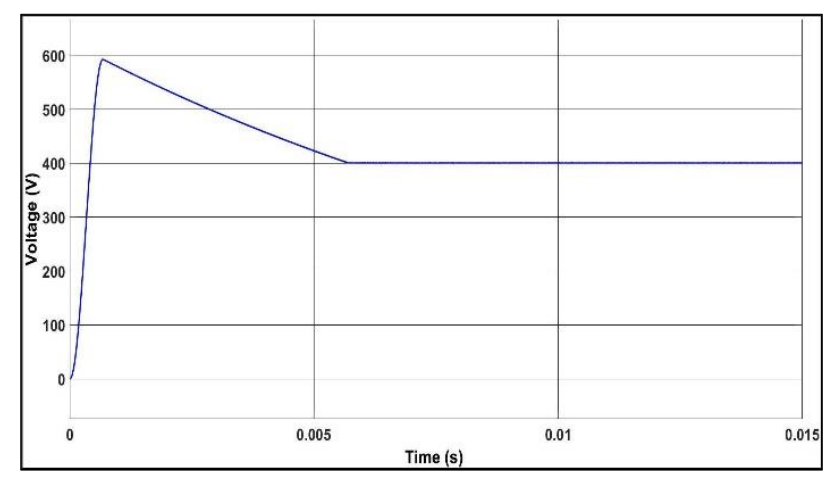

Figure 10 - Output voltage of the boost converter at an input voltage of $300 \mathrm{~V}$

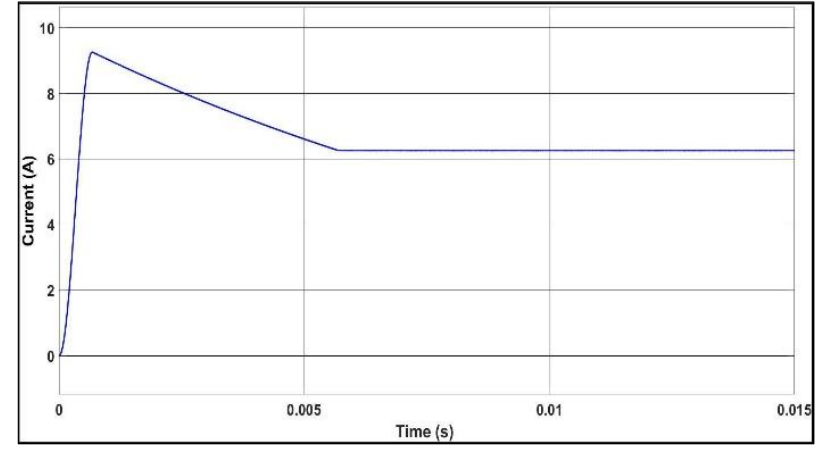

Figure 11 - Output current of the Boost Converter

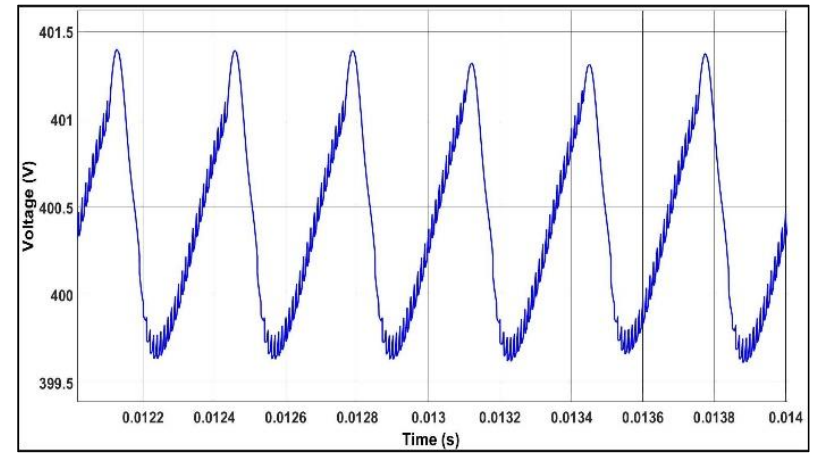

Figure 12 - Ripple component in the output voltage of Boost Converter

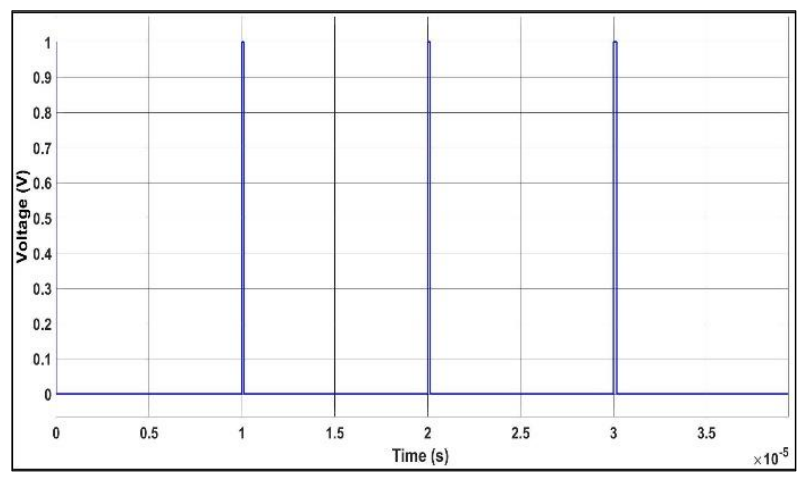

Figure 13 - PWM Pulses generation

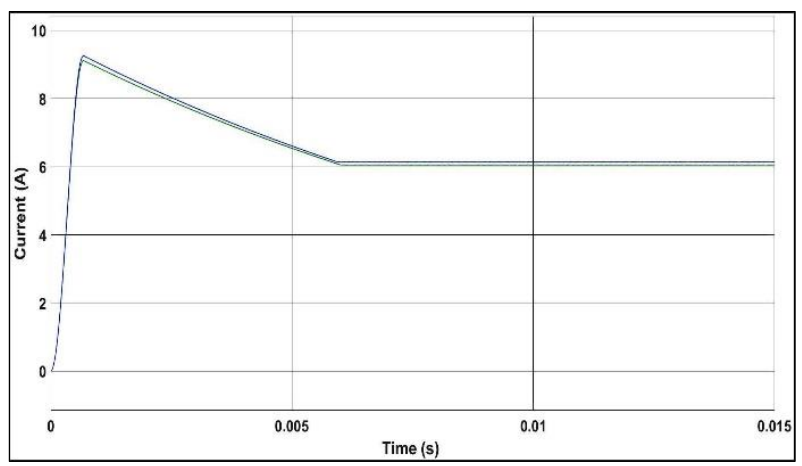

Figure 14 - Current sharing of the two parallelly connected converters 


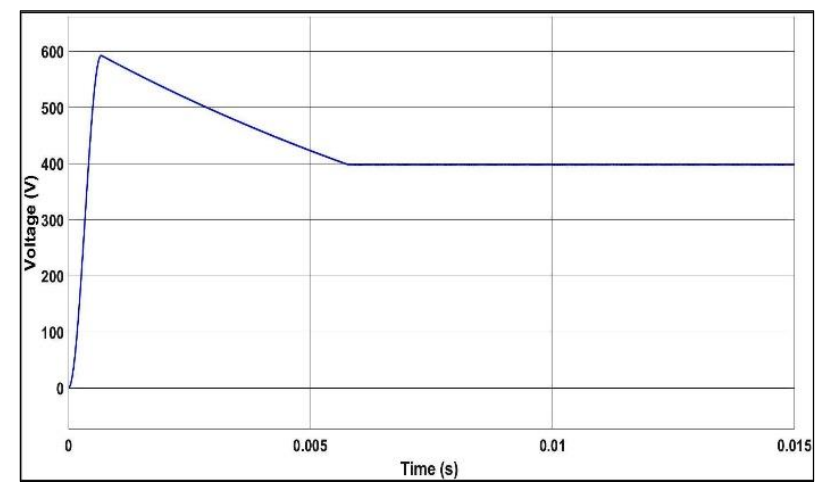

Figure 15 - Output voltage of the boost converter at an input voltage of $220 \mathrm{~V}$

Table 2 shows the output voltage and load current with a constant duty cycle. Here, it is observed that the output voltage slightly increased with a decrease in loads. Table 3 shows the various electrical parameters of the converter with the varying duty cycle. Here, it is observed that the voltage and current almost maintained a constant value with the variation of the duty cycle.

Fig. 10 and Fig. 11 show that the converter boosts the voltage from $300 \mathrm{~V}$ to $400 \mathrm{~V}$ with a full load current of 6.25 A. Therefore, the RESs can be easily integrated with the DC grid. Furthermore, the settling time of the output voltage is less than $10 \mathrm{~ms}$. Fig. 12 shows the ripple in the converter's output voltage is around is $1.8 \mathrm{~V}$ which minimizes the ripple component of the sources' original output voltage. Moreover, the PWM signal is generated with the PWM generator's help in MATLAB Simulink to switch MOSFET, as shown in Fig. 13. From Table 2, it is seen that at duty cycle 0.44 , the converter's output voltage is maintained constant throughout, and the current increases with the increase of load. From Table 3, it can be said that the current and the voltage are almost maintained constant. Fig. 14 shows the sharing of current by two converters when connected in parallel. It shows a slight variation in current sharing with the load. Fig. 15 shows the output voltage of $400 \mathrm{~V}$ with the minimum input voltage of $220 \mathrm{~V}$.

\section{Conclusion}

In this paper, an HV DC-DC Converter has been designed in MATLAB Simulink with an automated Digital controller. The converter has been designed for the operation with renewable energy sources in a practical DC microgrid. As the full load output voltage of the sources varies within a wide range, the converter does manage the considerable variation to main the constant level in the bus voltage. The efficiency of any power source can be increased with the help of this converter. In this paper, the Digital controller has been used in the HV DC-DC Boost converter's current mode control. The digital control method is advantageous for any converter associated with the microgrid operation. With this control operation's help, data can be sent or stored in the system for further operation.

The stability of the system can also be easily maintained with this converter. The different electrical parameters have been shown graphically in this work. The problems of voltage and ripple faced in this type of renewable energy power source can overcome with this digitally-controlled converter scheme for the DC Microgrid.

The ripple in the output voltage can be minimized over a wide range.

\section{Acknowledgments}

The authors are thankful to the Centre of Excellence for Green Energy and Sensor Systems of the Indian Institute of Engineering Science and Technology (IIEST), Shibpur, to collect data for the research.

\section{References}

1. Lotfi, H., Khodaei, A. (2017). AC Versus DC Microgrid Planning. IEEE Transactions on Smart Grid, Vol. 8(1), pp. 296-304, doi: 10.1109/TSG.2015.2457910.

2. Wang B., Sechilariu M., Locment F. (2012). Intelligent DC Microgrid With Smart Grid Communications: Control Strategy Consideration and Design. IEEE Transactions on Smart Grid, Vol. 3(4), pp. 2148-2156, doi: 10.1109/TSG.2012.2217764.

3. Samanta H., Pramanik M., Das A., Bhattacharjee A., Bhattacharya K. D., Deb N. K., Sengupta S., Saha H. (2019). Development of a novel controller for DC-DC boost converter for DC Microgrid. TENCON 2019 - 2019 IEEE Region 10 Conference (TENCON), pp. 1124-1129, doi: 10.1109/TENCON.2019.8929521.

4. Radwan A. A. A., Mohamed Y. A-R. I. (2012). Linear Active Stabilization of Converter-Dominated DC Microgrids. IEEE Transactions on Smart Grid, Vol. 3(1), pp. 203-216, doi: 10.1109/TSG.2011.2162430.

5. Lonkar M., Ponnaluri S. (2015). An Overview of DC Microgrid Operation and Control. IREC2015 The Sixth International Renewable Energy Congress, pp. 1-6, doi: 10.1109/IREC.2015.7110892.

6. Sarkar T., Bhattacharjee A., Samanta H., Bhattacharya K., Saha H. (2019). Optimal design and implementation of solar PV-windbiogas-VRFB storage integrated smart hybrid microgrid for ensuring zero loss of power supply probability. Energy Conversion and Management, Vol. 191, pp. 102-118, doi: 10.1016/j.enconman.2019.04.025.

7. Nejabatkhah F., Li Y. W. (2015). Overview of Power Management Strategies of Hybrid AC/DC Microgrid. IEEE Transactions on Power Electronics, Vol. 30(12), pp. 7072-7089, doi: 10.1109/TPEL.2014.2384999.

8. Liu X., Wang P., Loh P. C. (2011). A Hybrid AC/DC Microgrid and Its Coordination Control. IEEE Transactions on Smart Grid, Vol. 2(2), pp. 278-286, doi: 10.1109/TSG.2011.2116162. 
9. Alassi A., Banales S., Ellabban O., Adam G., MacIver C. (2019). HVDC Transmission: Technology Review, Market Trends and Future Outlook. Renewable and Sustainable Energy Reviews, Vol. (112), pp. 530-554, doi: 10.1016/j.rser.2019.04.062.

10. Khorsandi A., Ashourloo M., Mokhtari H. (2014). A Decentralized Control Method for a Low-Voltage DC Microgrid. IEEE Transactions on Energy Conversion, Vol. 29(4), pp. 793-801, doi: 10.1109/TEC.2014.2329236.

11. Strunz K., Abbasi E., Huu D. N. (2014). DC Microgrid for Wind and Solar Power Integration. IEEE Journal of Emerging and Selected Topics in Power Electronics, Vol. 2(1), pp. 115-126, doi: 10.1109/JESTPE.2013.2294738.

12. Justo J. J., Mwasilu F., Lee J., Jung J-W. (2013). AC-microgrids versus DC-microgrids with distributed energy resources: A review. Renewable and Sustainable Energy Reviews, Vol. 24, pp. 387-405, doi: 10.1016/j.rser.2013.03.067.

13. Gupta A., Kondekar P. N. (2019). An On-Chip Digital Soft-Start Circuit for Integrated DC-DC Buck Converter. 2019 10th International Conference on Computing, Communication and Networking Technologies (ICCCNT), pp. 1-5, doi: 10.1109/ICCCNT45670.2019.8944561.

14. Alexandru I. C., Mircea B. (2019). Analysis and design of a current mode buck converter with digitally controlled output voltage. 2019 International Semiconductor Conference (CAS), pp. 309-312, doi: 10.1109/SMICND.2019.8923781.

15. SEO S-W., CHOI H. H. (2019). Digital Implementation of Fractional Order PID-Type Controller for Boost DC-DC Converter. IEEE Access, Vol. (7), pp. 142652-142662, doi: 10.1109/ACCESS.2019.2945065.

16. Chen D., Xu L. (2012). Autonomous DC Voltage Control of a DC Microgrid With Multiple Slack Terminals. IEEE Transactions on Power Systems, Vol. 27(4), pp. 1897-1905, doi: 10.1109/TPWRS.2012.2189441.

17. Djamel O., Dhaouadi G., Youcef S., Mahmoud M. (2019). Hardware Implementation of Digital PID Controller for DC-DC Boost Converter. 2019 4th International Conference on Power Electronics and their Applications (ICPEA), pp. 1-4. doi: 10.1109/ICPEA1.2019.8911129.

18. Chen D., Xu L. (2011). Control and Operation of a DC Microgrid With Variable Generation and Energy Storage. IET Conference on Renewable Power Generation (RPG 2011), Vol. 26(4), pp. 2513-2522, doi: 10.1109/TPWRD.2011.2158456.

19. Padmanaban S., Kabalci E., Iqbal A., Abu-Rub H., Ojo O. (2015). Control strategy and hardware implementation for DC-DC boost power circuit based on proportional-integral compensator for high voltage application. Engineering Science and Technology, an International Journal, Vol. 18(2), pp. 163-170, doi: 10.1016/j.jestch.2014.11.005.

20. Benavides N. D., Chapman P. L. (2008). Modeling the Effect of Voltage Ripple on the Power Output of Photovoltaic Modules. IEEE Transactions on Industrial Electronics, Vol. 55(7), pp. 2638 - 2643. doi: 10.1109/TIE.2008.921442.

21. Benda D., Vorel P. (2019). Experimental DC/DC Converter for Photovoltaic Panel with Fully Digital Control Based on Flyback Topology with Nontraditional Snubber Circuit. 2019 International Conference on Electrical Drives \& Power Electronics (EDPE), pp. 120-124, doi: 10.1109/EDPE.2019.8883875.

22. Mohod S. W., Padgavhankar A. V. (2013). Closed Loop Digital Controller of DC-DC Converter for Renewable Energy Source (PV Cell). 2013 International Conference on Renewable Energy and Sustainable Energy(ICRESE), pp. 112-116, doi: 10.1109/ICRESE.2013.6927798.

23. Etz R., Petreus D., Moga D., Abrudean M., Patarau T. (2012). Fuzzy Digital Control for DC-DC Converters Used in Renewable Energy Systems. IFAC Proceedings Volumes, Vol. 45(21), pp. 91-96. doi: 10.3182/20120902-4-FR-2032.00018.

24. Ugur A., Yilmaz M. (2019). Digital hybrid current mode control for DC-DC converters. IET Power Electronics, Vol. 12(4), pp. 891-898, doi: 10.1049/iet-pel.2018.6035.

25. Basic Calculation of a Boost Converter's Power Stage. Texas Instruments - https://www.ti.com/.

26. Syed Abdul Rahman Kashif (2021). Digitally Controlled Buck Converter (https://www.mathworks.com/matlabcentral/fileexchange/27382-digitally-controlled-buck-converter), MATLAB Central File Exchange. Retrieved January 23, 2021. 